\title{
A STUDY ON EFFECT OF INDOLE AS A SUBSTITUENT ON A KETO-ENOL TAUTOMER: A SYNTHETIC APPROACH ON $\beta$-DIKETONE
}

\author{
KRISHNAKUMAR K. L. ${ }^{1 *}$, MATHEW PAUL UKKEN², MANJU R. ${ }^{3}$
}

1Department of Pharmaceutical Chemistry, Acharya and BM Reddy College of Pharmacy, Chikkabanavara, Bengaluru 560107, Karnataka, India, ${ }^{2}$ Department of Chemistry, Christ College, Irinjalakuda 680125, Kerala, India, ${ }^{3}$ Department of Pharmaceutical Chemistry, Nirmala College of Health Science, Chalakudy 680311, Kerala, India

Email: krishnakumarkl@gmail.com

Received: 02 May 2017 Revised and Accepted: 30 Jun 2017

ABSTRACT

Objective: The existence of keto-enol tautomerism in $\beta$-diketones can typically study by a choice of analytical technique. The position of the ketoenol equilibrium depends on a number of factors like solvent, temperature, and substituents. Here an attempt was made to examine the effect of indole, a heterocyclic moiety with the moderately high polar surface area to examine its effect on ketonisation of $\beta$-diketone.

Methods: The $\beta$-diketone studied and synthesized is a structural analog of magical drug curcumin. The structural influence of indole on ketonisation of $\beta$-diketone is studied to give a hypothesis on factors contributing towards ketonisation. This work involves the synthesis of 6 - $(1 H-$ Indol-3-yl)-hex-5ene-2, 4-dione and the study on the single crystal structure of indole-3-carboxaldehyde, major functional component to result in the reaction. The tautomer was studied for its ability to bind with tetrahydrofolate reductase enzyme using Discovery Studio 3.5 version to differentiate the pharmacological significance of conformations.

Results: The single crystal XRD structure of this compound was deposited in Cambridge crystallographic data center bearing CCDC No.1536311. The structural characterization of synthesized ligand was carried out by using IR, Mass, ${ }^{1} \mathrm{H}$ NMR spectroscopic techniques. The docking study reveals that keto isomer found to exhibit more inhibition of the enzyme tetrahydrofolate reductase hence more pharmacologically active.

Conclusion: The experimental evidence proves that indole substitution shifted the keto-enol equilibrium towards keto form of 6-(1H-Indol-3-yl)hex-5ene-2, 4-dione.

Keywords: Keto-enol tautomerism, $\beta$-diketones, 6-(1H-Indol-3-yl)-hex-5ene-2, 4-dione, Structural analog, Curcumin, Single crystal XRD, IR, Mass, ${ }^{1} \mathrm{H}$ NMR, Docking

(C) 2017 The Authors. Published by Innovare Academic Sciences Pvt Ltd. This is an open access article under the CC BY license (http://creativecommons.org/licenses/by/4.0/) DOI: http://dx.doi.org/10.22159/ijpps.2017v9i8.19576

\section{INTRODUCTION}

Curcuminoids, the active chemical components present in Indian medicinal plant turmeric (Curcuma Longa, Linn, Zingiberaceae family) have various biological activities, including antioxidant, antiinflammatory, anti-arthritic and anti-tumor activities [1, 2]. The potential health benefits of curcumin are limited by its poor solubility, low absorption from the gut, rapid metabolism and rapid systemic elimination [3]. Curcumin adjuvant therapy, solid dispersion, liposomal curcumin and synthetic analogs of curcumin are a few methods used to overcome these drawbacks [4]. Out of this, the synthetic analogs and their pharmacological screening are studied vastly in the past few decades [5]. The structure (fig. 1) can be related to a series of similar molecules which resulted as an attempt to synthesize synthetic curcumin of 6-aryl-5-hexene-2, 4diones series [6, 7]. Structurally, this is $\alpha, \beta$-unsaturated 1,3 diketone with an indole substitution on its left terminal. A series of aromatic and heteroaromatic compounds were already counted under this class proved to exist in enol form [8]. The same synthetic route, when tried with $1 H$-indole-3-carboxaldehyde gave a conflict.

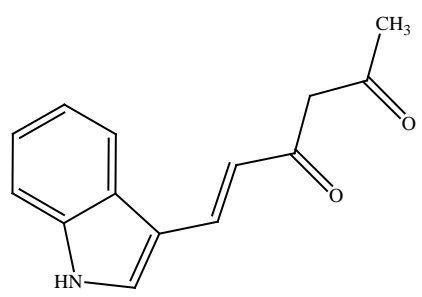

Fig. 1: Structure of 6-(1H-Indol-3-yl)-hex-5-ene-2, 4-dione
Normal $\beta$-ketones have a tendency to exist in enol, as it is more stable. This can be explained by considering the ability of enol form to contribute stable six-membered cyclic structures through hydrogen bonding as shown in structure (fig. 2). Studies suggest that the amount of Enol form decreases when a bulky alkyl substituent present at the $\alpha$-position [9]. Bulky alkyl groups such as the isopropyl group or the Sec-butyl group decrease the quantity of enol form to almost $0 \%$. The presence of an alkyl substituent on the $\alpha$-carbon decreases the amount of enol form. The bearing of a chlorine group at the $\alpha$-position increases the amount of enol form to $92 \%$. According to Burdett and Rogers [10], the presence of electron-withdrawing groups, such as $\mathrm{CF}_{3}$ favors the enol form. When four or iflooeine atoms are present in the molecule, the enolization is complete. Also, phenyl groups favor the enol form. The lower the polarity of the solvent, the higher is the percent of the enol form. In CCl4, 94\% of the acetylacetone molecules are present in the enol form, whereas in acetonitrile this value is scaled down to $36 \%$. The amount of enol form decreases with increasing temperatures. The NMR study of solution structures of curcumin in solvents ranging in polarity from $\mathrm{CDCl} 3$ to mixtures of DMSO-d6 in water, and in buffered aqueous DMSO- $d 6$ solutions with $\mathrm{pH}$ values varying from 3 to 9 , found that curcumin exists in solution as keto-enol tautomer, The titrimetric chloramine-T oxidative methods were used earlier for the determination of percentage of enol form of in the $\beta$ dicarbonyl compounds $[11,12]$. The ability of these $\beta$-keto compounds to involve in the synthesis of medicinally active heterocyclic compounds were studied extensively in past few years $[13,14]$. But when it comes to $\beta$-dicarbonyl compounds in the solid state, use of spectroscopic methods like ${ }^{1} \mathrm{H}$ NMR, single crystal XRD methods has to be used sensibly to distinguish the confirmation. 


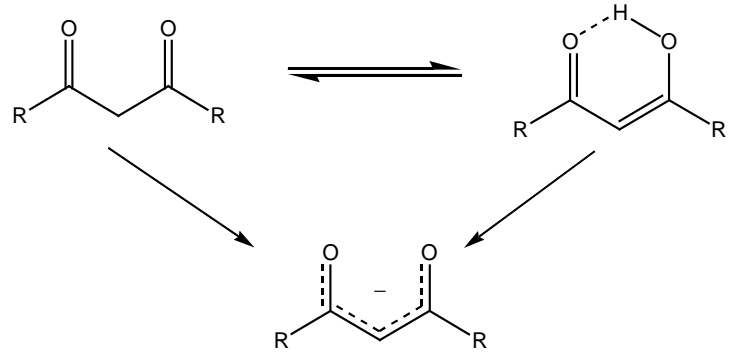

Fig. 2: Keto-enol tautomerism in $\beta$-ketones

It was interesting to note that indole; a bicyclic heterocyclic ring system has not reported contributing an impact on keto existence of diketone in any of this literature. This can be explored only by considering indole as a substituent on $\beta$-diketone, which is broadly studied for its substitution with aliphatic and aromatic groups. The available literature of substitution with benzaldehyde with the less polar surface area to vaniline with more polar surface area show the shift of equilibrium towards enolization. One such example 6-aryl-5hexene-2, 4-diones (fig. 3) being a synthetic analog of curcumin was studied vast in previous years $[15,16]$

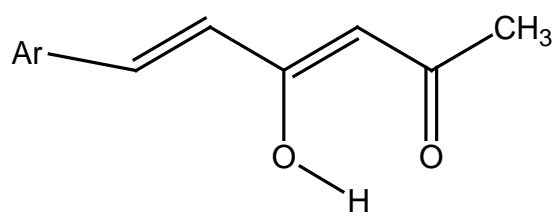

Fig. 3: Structure of 6-aryl-5-hexene-2, 4-diones

Curcumin research on synthetic analogs now turned into a stage, where researchers have to focus on identification of pharmacophore which needs to be altered for improving the efficacy as a drug candidate. There has an ongoing debate regarding $\alpha, \beta$-unsaturated diketone system exists on curcumin as the reason for magical effect of the drug [17]. The keto-enol isomeric effect on structural pharmacophore may play an important role in binding of this analog with drug target. The relationship between tautomeric structures of curcumin and its effect on neurodegenerative diseases like Alzheimer's was the research of interest for the present [18]. So the initial efforts were taken to study the effect of indole by synthesis of 6-aryl-5-hexene-2, 4-diones using $1 H$-indole-3-carboxaldehyde. This special case captured attention while trying to synthesise a novel series of heteroaryl hexanoids using different heterocyclic aldehydes. So here focus was given on indole as a special case which demonstrated a change in structural geometry of synthetic analogs of this series. Efforts were made to study this reason by altering reaction conditions and reagent concentrations. The single crystal XRD structure of $1 H$-indole-3-carboxaldehyde is studied for its influence on bond angle and bond length on ketonisation. The ongoing research in this field suggests that proteinaceous drug receptors frequently preferentially bind a tautomer that is present in low abundance in water [19]. So the proper treatment of molecules that can tautomerize them either keto or enol form is a challenge for medicinal chemist.

Dihydrofolate reductase, one of the targets for antifolate-based drugs has been validated by researchers for the screening of pharmacological activities in related compounds [20]. The drug, which is a potent inhibitor of dihydrofolate reductase (DHFR) acts by preventing the synthesis of tetrahydro folic acid and inhibiting cell growth and multiplication. The surviving evidence from docking studies on this heated discussion of pharmacological activities of ketoenol forms favours keto form in case of curcumin [21]. The same approach on 6-(1H-Indol-3-yl)-hex-5ene-2, 4-dione, a synthetic analog of curcumin by using dihydrofolate reductase enzyme will shed light on synthetic chemist who works on modification of these analogs.

\section{MATERIALS AND METHODS}

All the chemicals utilized in this study were AR grade purchased from Sigma-Aldrich. Melting points were determined by open tube capillary method and are uncorrected. Instruments used in this investigation are UV-1601 Shimadzu recording spectrophotometer, Thermo Nicolet, Avatar 370 FTIR spectrophotometer, Jeol/Sx-102(FAB) mass spectrometer, Varian, Mercury Plus $300 \mathrm{MH}_{\mathrm{z}}$ NMR spectrophotometer, Bruker Kappa Apex II diffractometer. The keto and enol conformations are docked using Accelrys Drug Discovery Studio 3.5. The structure of the enzyme tetrahydrofolate reductase complexes was obtained from a Protein data bank (PDB code: 7DFR) and was used for docking. The chain-A is retained and the crystal structure was cleaned by deleting the ligands and other heteroatoms. The prepared ligands were docked by using CDocker. Docking calculations were carried out using Accelrys Drug Discovery Studio (3.5version).

\section{Experimental}

Synthesis of 6-(1H-Indol-3-yl)-hex-5ene-2, 4-dione [22-24]

Acetylacetone $(0.075 \mathrm{~mol})$ mixed with boric oxide was suspended in dry ethyl acetate $(50 \mathrm{ml})$ containing tri (sec-butyl) borate $(0.1 \mathrm{~mol})$. To this combination kept at about $0{ }^{\circ} \mathrm{C}$, a solution of $1 \mathrm{H}$-indole-3carboxaldehyde $(0.025 \mathrm{~mol})$ in dry ethyl acetate $(15 \mathrm{ml})$ and n-butyl amine $(0.5 \mathrm{ml})$ was added dropwise for 90 min with continuous stirring. The stirring was continued for an extra period of about $2 \mathrm{~h}$ and the solution was set aside all night. The reaction mixture was then stirred for about $1 \mathrm{~h}$ with hot $\left(50^{\circ} \mathrm{C}\right)$ hydrochloric acid $(0.4 \mathrm{M}$, $20 \mathrm{ml}$ ) and extracted over and over again with ethyl acetate. The collective extracts were concentrated under vacuum and purified by column chromatography (silica gel, mesh 60-120). The yellow band developed in the lower section was recovered by successive elution with $5: 1 \mathrm{v} / \mathrm{v}$ mixture of chloroform-acetone and the combined eluates on evaporation yielded 6-(1H-Indol-3-yl)-hex-5ene-2, 4dione. Scheme of synthesis outlined below. (fig. 4) The isolated 6(1H-Indol-3-yl)-hex-5ene-2, 4-dione was recrystallized from hot benzene to get chromatographically (TLC) pure material. The unreacted $1 H$-indole-3-carboxaldehyde was separately eluted from the reaction mixture using the same solvent system and used for crystal study.<smiles>O=Cc1c[nH]c2ccccc12</smiles><smiles>CC(=O)CC(C)=O</smiles>
$\downarrow \begin{aligned} & \mathrm{B}_{2} \mathrm{O}_{3} \text { Tri(sec-butyl)borate } \\ & \mathrm{n}-\mathrm{BuNH}_{2}\end{aligned}$<smiles>CC(=O)CC(=O)/C=C/c1c[nH]c2ccccc12</smiles>

Fig. 4: Scheme of synthesis of 6-(1H-Indol-3-yl)-hex-5-ene-2, 4dione

\section{Single crystal study}

The unreacted $1 H$-indole-3-carboxaldehyde was separated by column chromatographic method using 5:1 v/v mixture of chloroform-acetone from the reaction mixture and used for crystal preparation. Deep yellow plate-like crystal of $1 H$-indole-3carboxaldehyde was prepared by crystallization of the compound from a mixture of ethanol-toluene-ethyl acetate mixture. The compound was dissolved in the solvent mixture at room temperature in a $50 \mathrm{ml}$ conical flask and the mouth was closed with 
cotton to allow slow evaporation of the solvent and kept aside for about $2 \mathrm{w}$ when a plate-like crystal was separated. A crystal with $0.40 \times 0.30 \times 0.20 \mathrm{~mm}$ was used for obtaining X-ray diffraction data. XRD data were collected on a Bruker Kappa Apex II diffractometer. To solve the structure all crystallographic calculations were performed using Shelxl program package.

\section{RESULTS}

\section{Characterization of 6-(1H-Indol-3-yl)-hex-5ene-2, 4-dione}

The derivatives were recrystallized from hot benzene to get chromategraphically (TLC) pure material to yield product (60\%) in the yellow to orange crystalline form. The UV absorption band $280 \mathrm{~nm}$, IR (v) 1668 ( $\mathrm{C}=0$ acetyl stretch), $1635.5 \quad(\mathrm{C}=0$ cinnamoyl stretch), 1518.8 (asymmetrical C-C-C chelate ring stretch), 1443.3 (symmetrical C-C-C chelate ring stretch), 997.2 ( $\mathrm{CH}=\mathrm{CH}$ stretch); $1 \mathrm{H}$ NMR $\delta 3.3$ (s, 3H,-CH3), 4.9 (s, 2H,-CH2), 7.3 (td, 4H, Ar H-4, H-5, H-6, H-7, J=3.50 Hz), 7.5(d,1H, $\mathrm{CH},-\alpha, \beta$-unsaturated, J=8.0 Hz), 8.1 (s,1H, $\mathrm{Ar} \mathrm{H}-2), 8.2(\mathrm{~d}, 1 \mathrm{H}, \mathrm{C}=\mathrm{CH}, \mathrm{J}=7.0$ $\mathrm{Hz}$ ), $9.9(\mathrm{~s}, 1 \mathrm{H},-\mathrm{NH}) ; \mathrm{EIMS} \mathrm{m} / \mathrm{z} 227$ [C14H13NO2]+, $170.06\left[\mathrm{C}_{11} \mathrm{H}_{8} \mathrm{NO}\right]+$, $129.06\left[\mathrm{C}_{9} \mathrm{H}_{7} \mathrm{~N}\right]+, 117.0\left[\mathrm{C}_{8} \mathrm{H}_{7} \mathrm{~N}\right]+$; Accurate mass found [C14H13NO2]+: $\mathrm{m} / \mathrm{z} 227.0$, calculated for $\left[\mathrm{C}_{14} \mathrm{H}_{13} \mathrm{NO}_{2}\right]+; 227.09$.

\section{Crystallographic study}

The ORTEP view and PLATON diagram (Shelxl program) of the molecule with the labeling of non-hydrogen atoms are shown in fig. 5 and fig. 6.

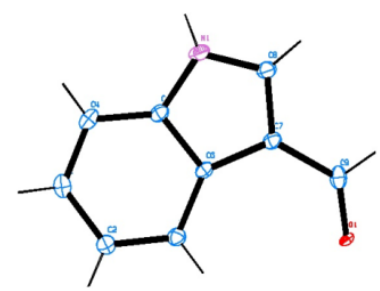

Fig. 5: $1 H$-indol-3-carboxaldehyde

\section{Docking studies on isomer}

The extent of biological activity variance on confirmations is studied by docking the keto-enol conformations against the selected enzyme dihydrofolate reductase. The amount of inhibition made by the conformations is studied by evaluating the result obtained after docking the conformations separately by using CDocker program. The CDocker energy and CDocker interaction energy were calculated. The scoring functions and hydrogen bonds formed with the surrounding amino acids are used to predict their level of inhibition on binding sites of dihydrofolate reductase receptor. The types and number of interactions between the synthesized ligand and enol confirmation were shown in fig. 8-9 (Discovery Studio 3.5, CDocker program). The CDocker energy, CDocker interaction energy for first three leads and number of hydrogen bond length are listed in table 2-3.

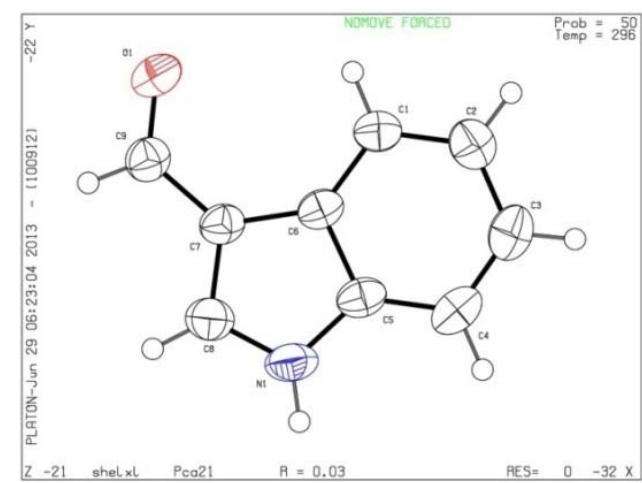

Fig. 6: $1 H$-indol-3-carboxaldehyde (PLATON)

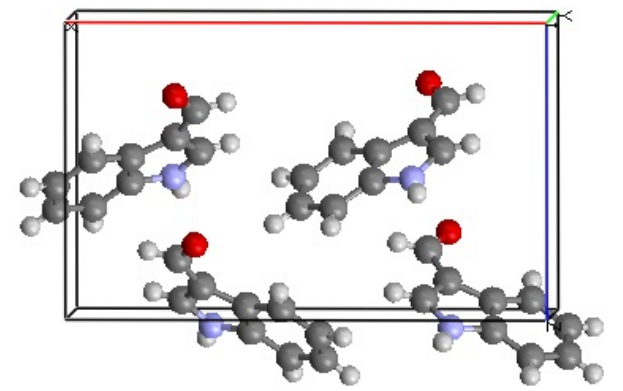

Fig. 7: Arrangement of molecule in crystal of $1 \mathrm{H}$-indol-3carboxaldehyde

Crystal data and structure refinement: $1 H$-indole-3-carboxaldehyde

\begin{tabular}{|c|c|}
\hline Identification code & shelxl \\
\hline Empirical formula & $\mathrm{C}_{9} \mathrm{H}_{7} \mathrm{NO}$ \\
\hline Formula weight & 145.16 \\
\hline Temperature & $296(2) \mathrm{K}$ \\
\hline Wavelength & $0.71073 \mathrm{~A}$ \\
\hline Crystal system, space group & Orthorhombic, Pca21 \\
\hline Unit cell dimensions & $\begin{array}{l}\mathrm{a}=14.0817(11) \text { A alpha }=90 \mathrm{deg} . \\
\mathrm{b}=5.8006(5) \mathrm{A} \text { beta }=90 \mathrm{deg} . \\
\mathrm{c}=8.6895(6) \text { A gamma }=90 \mathrm{deg} .\end{array}$ \\
\hline Volume & $709.78(10) A^{\wedge} 3$ \\
\hline $\mathrm{Z}$, Calculated density & $4,1.358 \mathrm{Mg} / \mathrm{m}^{\wedge} 3$ \\
\hline Absorption coefficient & $0.090 \mathrm{~mm}^{\wedge}-1$ \\
\hline Crystal size & $0.40 \times 0.30 \times 0.20 \mathrm{~mm}$ \\
\hline Theta range for data collection & 2.89 to 28.35 deg. \\
\hline Limiting indices & $-18<=\mathrm{h}<=15,-7<=\mathrm{k}<=7,-11<=\mathrm{l}<=8$ \\
\hline Reflections collected/unique & $5287 / 1617[\mathrm{R}(\mathrm{int})=0.0236]$ \\
\hline Completeness to theta $=28.35$ & $100.0 \%$ \\
\hline Absorption correction & Semi-empirical from equivalents \\
\hline Max. and min. transmission & 0.9822 and 0.9648 \\
\hline Refinement method & Full-matrix least-squares on $\mathrm{F}^{\wedge} 2$ \\
\hline Data/restraints/parameters & $1617 / 1 / 101$ \\
\hline Goodness-of-fit on $\mathrm{F}^{\wedge} 2$ & 0.549 \\
\hline Final R indices [I>2sigma(I)] & $\mathrm{R} 1=0.0341, \mathrm{wR} 2=0.1021$ \\
\hline $\mathrm{R}$ indices (all data) & $\mathrm{R} 1=0.0422, \mathrm{wR} 2=0.1176$ \\
\hline Absolute structure parameter & $-1(2)$ \\
\hline Extinction coefficient & $0.048(8)$ \\
\hline Largest diff. peak and hole & 0.159 and -0.138 e. $A^{\wedge}-3$ \\
\hline
\end{tabular}


Table 1: Bond angles and bond lengths

\begin{tabular}{|c|c|c|c|}
\hline Atom to atom & Bond lengths $\left[\mathrm{A}^{\circ}\right]$ & Atom to atom & Bond angles (deg) \\
\hline $\mathrm{O}(1)-\mathrm{C}(9)$ & 1.217 & $C(1)-C(6)-C(5)$ & 118.77 \\
\hline$C(6)-C(1)$ & 1.391 & $C(1)-C(6)-C(7)$ & 134.99 \\
\hline$C(6)-C(5)$ & 1.404 & $C(5)-C(6)-C(7)$ & 106.12 \\
\hline$C(6)-C(7)$ & 1.439 & $C(2)-C(1)-C(6)$ & 118.71 \\
\hline$C(1)-C(2)$ & 1.380 & $\mathrm{C}(2)-\mathrm{C}(1)-\mathrm{H}(1)$ & 120.6 \\
\hline $\mathrm{C}(1)-\mathrm{H}(1)$ & 0.930 & $\mathrm{C}(6)-\mathrm{C}(1)-\mathrm{H}(1)$ & 120.6 \\
\hline$C(9)-C(7)$ & 1.423 & $\mathrm{O}(1)-\mathrm{C}(9)-\mathrm{C}(7)$ & 124.99 \\
\hline $\mathrm{C}(9)-\mathrm{H}(9)$ & 0.930 & $\mathrm{O}(1)-\mathrm{C}(9)-\mathrm{H}(9)$ & 117.5 \\
\hline$C(7)-C(8)$ & 1.380 & $\mathrm{C}(7)-\mathrm{C}(9)-\mathrm{H}(9)$ & 117.5 \\
\hline$C(5)-C(4)$ & 1.388 & $C(8)-C(7)-C(6)$ & 106.15 \\
\hline $\mathrm{C}(5)-\mathrm{N}(1)$ & 1.377 & $\mathrm{C}(8)-\mathrm{C}(7)-\mathrm{C}(9)$ & 123.62 \\
\hline$C(2)-C(3)$ & 1.391 & $C(6)-C(7)-C(9)$ & 130.20 \\
\hline $\mathrm{C}(2)-\mathrm{H}(2)$ & 0.930 & $\mathrm{C}(4)-\mathrm{C}(5)-\mathrm{N}(1)$ & 129.26 \\
\hline$N(1)-C(8)$ & 1.335 & $C(4)-C(5)-C(6)$ & 122.65 \\
\hline $\mathrm{N}(1)-\mathrm{H}(5)$ & 0.860 & $N(1)-C(5)-C(6)$ & 107.99 \\
\hline $\mathrm{C}(8)-\mathrm{H}(8)$ & 0.930 & $C(1)-C(2)-C(3)$ & 121.23 \\
\hline$C(3)-C(4)$ & 1.369 & $\mathrm{C}(1)-\mathrm{C}(2)-\mathrm{H}(2)$ & 119.4 \\
\hline $\mathrm{C}(3)-\mathrm{H}(3)$ & 0.930 & $\mathrm{C}(3)-\mathrm{C}(2)-\mathrm{H}(2)$ & 119.4 \\
\hline $\mathrm{C}(4)-\mathrm{H}(4)$ & 0.930 & $\mathrm{C}(8)-\mathrm{N}(1)-\mathrm{C}(5)$ & 109.34 \\
\hline
\end{tabular}

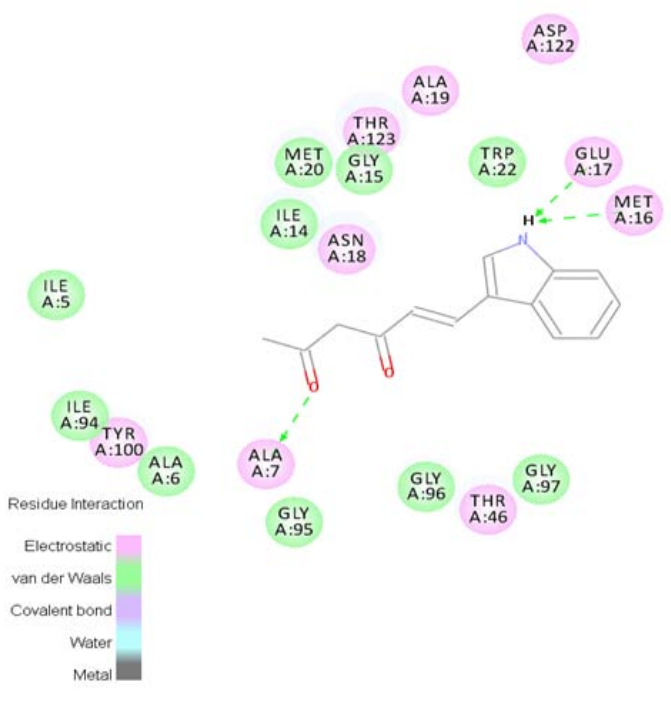

Fig. 8: Binding configuration of keto isomer

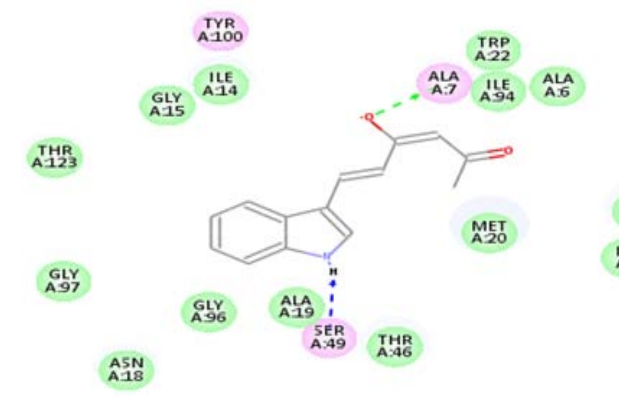

Residue Interaction

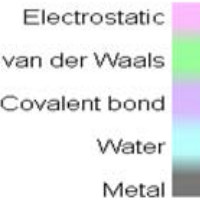

Fig. 9: Binding configuration of enol isomer 
Table 2: Statistical docking results of keto isomer (discovery studio 2.5 software)

\begin{tabular}{lll}
\hline CDocker energy & CDocker interaction energy & Nature of Hydrogen bond \\
\hline-31.4535 & -35.2347 & A: ALA7: HN-Molecule: 016 \\
-28.7751 & -35.1325 & Molecule: H30-A: MET16: O \\
-28.6988 & -31.5826 & Molecule: H30-A: GLU17: 0 \\
\hline
\end{tabular}

Table 3: Statistical docking results of enol isomer (discovery studio 2.5 software)

\begin{tabular}{lll}
\hline CDocker energy & CDocker interaction energy & Nature of Hydrogen bond \\
\hline-28.1646 & -34.8425 & A: ALA7: HN-Molecule: 017 \\
-27.887 & -35.0845 & Molecule: H29-A: SER49: OG \\
-27.5315 & -33.8704 & \\
\hline
\end{tabular}

\section{DISCUSSION}

The UV absorption band is very broad and shows the presence of more than one peak indicating the presence of more than one isomeric form in the ground state. The high energy band at $280 \mathrm{~nm}$ due to $\pi \rightarrow \pi^{*}$ transitions of the fully conjugated system is marginally influenced by indolyl groups. The IR spectra of the diketones show the prominent band at 1635.5 assignable to the cinnamoyl $\mathrm{v}(\mathrm{C}=\mathrm{C})$ vibrations. The observed position and intensity of these bands indicate that the compound exhibit strong shift to keto form. A medium intensity band at $997.2 \mathrm{~cm}^{-1}$ in the spectra of the compound can be assigned to the trans- $\mathrm{CH}=\mathrm{CH}$-absorption $[25,26]$. The proton magnetic resonance spectra indicated that the synthetic analog existed entirely in the keto form rather than the enol form in deutero-methanol solution. The signal due to methylene carbon of keto tautomer was observed as intense peek in $\delta$ value 4.9 [27]. The mass fragmentation patterns depend mainly on the nature of groups attached to the dike to function. Elimination of $\mathrm{O}, \mathrm{OH}, \mathrm{CO}, \mathrm{C}_{3} \mathrm{HO}_{2}{ }^{+}$, $\mathrm{CH}_{2}=\mathrm{C}=\mathrm{O}$ (ketene), etc are characteristic of acetylacetone and related 1, 3-diketones [28]. On common practice, the $\beta$-diketones prefer the cis enol configuration stabilized by a strong intramolecular hydrogen bond. The information gathered from above results was found contrary to the above statement. The XRD results reveal that the crystal crystallizes in orthorhombic system with lattice parameter values, $a=14.0817 \mathrm{~A}{ }^{\circ}, b=5.8006 \mathrm{~A}{ }^{\circ}, c$ $=8.6895 \mathrm{~A}^{\circ}$ with a slight marginal difference from reported XRD values of $1 \mathrm{H}$-Indole-3-carboxaldehyde $[29,30]$. This ruled out the possibility of polymorphism of crystals under high-temperature reaction condition. The data obtained from single crystal XRD study of $1 \mathrm{H}$-indol-3-carboxaldehyde used here to give evidence for keto existence. The unit cell parameters, experiment details, and refinement parameters are listed above. Analysis of bond length and bond angles (table 1) reveals that the molecule is planar with slightly tilted $\mathrm{C}=0$ bond with $\mathrm{O}(1)-\mathrm{C}(9)-\mathrm{H}(9)$ bond angle is $117.5^{\circ}$. It was attention-grabbing to identify that, normal $\mathrm{CHO}$ bond is trigonal planar with angle $120^{\circ}$. The $\mathrm{O}(1)-\mathrm{C}(9)$ bond length was found to pretty long $1.217 \mathrm{~A}{ }^{\circ}$. The comparison of XRD results of the title compound with reported aldehydes strongly suggests different geometry for $1 \mathrm{H}$-indol-3-carboxaldehyde. Further analysis of hydrogen bonding network in the crystal pattern of $1 \mathrm{H}$-indol-3carboxaldehyde reveals the presence of four molecules in unit cell as shown in fig. 7 (Shelxl program).

The docking energy scores suggest that the keto form of the ligand has slightly better binding energy values in comparison with the enol isomer of 6-(1H-Indol-3-yl)-hex-5ene-2, 4-dione. But upon examining the interactions with the active binding site of the receptor, the keto isomer has a number of prominent and strong electrostatic interactions with amino acid residues like ALA: 7, TYR: 100, ASN: 18, THR: 123, ALA: 19, ASP: 122, THR: 46, GLU: 17, MET: 16. In the case of enol derivative, major interactions are of weak Van der Waals kind. Further, it is interesting to notice that the keto isomer exhibit three hydrogen bonding interactions amino acid residues in the receptor namely ALA7: HN-Molecule: 016, Molecule: H30-MET16: 0 and the third one with the same hydrogen atom (H: 30) in the molecule with GLU: 17 . Whereas the third hydrogen bond from $\mathrm{NH}$ of the molecule is absent in enol isomer. Hydrogen bonds play a crucial role in defining the specificity of ligand binding. Most of the studies show that hydrogen bond and other polar interactions are playing important role in finding the proper orientation of the molecule to make maximum interactions [31]. The keto isomer was found to be more compact with three hydrogen bond interaction with amino acid residues exhibiting stronger inhibition of dihydrofolate reductase enzyme. In the enolic confirmation, the conjugated dienyl existence of molecule was thought to contribute some conformational changes in the molecule and hence steric hindrance. This steric hindrance may the reason more hydrophobic interaction and poor inhibition of enolic isomer with dihydrofolate reductase enzyme.

\section{CONCLUSION}

The results from IR band 1635.5 ( $\mathrm{C}=0$ cinnamoyl stretch) supports the ketonic existence of 6-(1H-Indol-3-yl)-hex-5ene-2, 4-dione. This is further supported by the fact observed in ${ }^{1} \mathrm{H}$ NMR spectrum with $\delta$ value 4.9 clearly corresponds to active methylene on $\alpha$ position of the $\beta$ diketone system. There was no peak at $\delta$ value 15 and above clearly ruled out the chance for the existence of enolic hydrogen. The hypothesis gave here based on literature survey and experimentation highly in favor with substituent effect of indole. Electronic effects or active polar surface area of the molecule has not found to play a major role on ketonisation. The experimentation with changing reactant concentration and reaction condition has not contributed to enolization with indole-3carboxaldehyde. Unlike other Carboxaldehyde, change in bond angle from normal trigonal $120^{\circ}$ along with intermolecular hydrogen bond exists between indole-3-carboxaldehyde has found to play a major role in this context. This has added significance as the tested indole-3carboxaldehyde used for crystal formation is extracted from reaction mixture used for preparation of 6-(1H-Indol-3-yl)-hex-5ene-2, 4-dione. All the available evidence in this study suggests the shift of equilibrium is more towards keto form. This equilibrium can be affected by other substitutions in the molecule. The effects of other substitution in indole and on $\beta$-diketone need to be studied in future. Further docking study performed on dihydrofolate reductase enzyme revealed that the keto isomer will be the best conformation with maximum binding and better predicted pharmacological activity.

\section{ACKNOWLEDGMENT}

Authors are thankful to the management of Christ College, Irinjalakuda, Kerala, Cochin University of Science and Technology, Kerala and Acharya and BM Reddy College of Pharmacy, Bengaluru for providing necessary facilities to carry out this work successfully.

\section{AUTHOR'S CONTRIBUTION}

Krishnakumar KL: Design of work, Literature review, synthetic part, drafting the article.

Mathew Paul Ukken: Data analysis, Revision of article.

Manju R: Revision of article and interpretation of results.

\section{CONFLICT OF INTERESTS}

\section{Declared none}

\section{REFERENCES}

1. Shaymaa HA, Manal KA, Akram AN. The potential benefit of curcumin adjuvant therapy to the standard helicobacter pylori 
eradication therapy in patients with peptic ulcer disease. Asian J Pharm Clin Res 2017;10:313-7.

2. Muhammad D, Andi S, Edi M, Umar AJ, Masashi K. Apoptosis induction effect of curcumin and its analogues pentagamavunon- 0 and pentagamavunon- 1 on cancer cell lines. Asian J Pharm Clin Res 2017;10:373-6.

3. Sarvesh S, Gaurav KS, Vimal K. Development of spectrophotometric methods for simultaneous determination of artesunate and curcumin in a liposomal formulation. Int J Appl Pharm 2015;7:18-21.

4. Rubendra K, Dinesh Kumar M, Dinesh Kumar J. Solid dispersion: a novel means of solubility enhancement. J Crit Rev 2016;3:1-8.

5. Karpakavalli M, Preethi K, Sanglimuthu A, Kumar EP. Docking, synthesis, characterization and anticancer activity of 4-(4'hydroxy, 3'-methoxy) phenyl, but-2-one-3-ene, a curcumin analogue precursor. Int J Curr Pharm Res 2016;8:1-5.

6. Mathew PU, Krishnankutty K. Synthesis, and characterization of $\mathrm{Co}$ (II), $\mathrm{Ni}(\mathrm{II})$ and $\mathrm{Cu}(\mathrm{II})$ complexes of some 6-aryl-5-hexene2,4-diones. Asian J Chem 2002;14:949-56.

7. John VD, Krishnankutty K. Antitumour studies aluminum complexes of synthetic curcuminoids. Main Group Met Chem 2010;33:157-65.

8. Mathew PU, Venugopalan P, Krishnankutty K. Metal chelates of 5-aryl-1-phenyl-4-pentene-1,3-diones. Asian J Chem 2002;14:1335-40.

9. Elgureo J, Marzin C, Katritzky AR, Linda P. Advances in heterocyclic chemistry: the tautomerism of heterocycles, Newyork: Academic Press; 1976.

10. Burdett JL, Rogers MT. Keto-enol tautomerism in $\beta$-dicarbonyls studied by nuclear magnetic resonance spectroscopy. J Am Chem Soc 1964;86:2105-9.

11. Umesha KB, Lokantha Rai KM, Ajay Kumar K, Sudha BS, Khanum SA. A new approach for the determination of the percentage of the enol form in the $\beta$-keto carbonyl compounds using the chloramineT oxidative method. Oxidation Commun 2004;27:831-5.

12. Umesha KB, Lokanatha Rai KM, Ajay Kumar K, Prasad KR, Shashikanth S. A new approach to the determination of a number of oxo groups in carbonyl compounds using the chloramine-T oxidative method. Chem Anal (Warsaw) 2001;46:269-74.

13. Umesha KB, Lokanatha Rai KM, Ajay Kumar K. A novel synthesis of isoxazoles via 1,3-dipoar cycloaddition of nitrile oxides to acetylacetone. Synthetic Commun 2002;32:1841-6.

14. Umesha KB, Lokanatha Rai KM, Ajay Kumar K. A new approach to the synthesis of pyrazoles via 1,3-dipolar cycloaddition of nitrile imines with acetylacetone. Indian J Chem 2002;41B:1450-3.

15. Krishnankutty K, Muhammed BU, Mathew PU. Some unsaturated $\beta$-diketones and their metal chelates. Trade Sci Inc 2009;4:78-82.

16. Muhammed BU, Anjali K, Mathew PU. Metal complexes of unsaturated poly carbonyl compounds derived from benzoyl acetone and aromatic aldehydes. J Iran Chem Res 2010;3:71-81.

17. Khan MA, El-Khatib R, Rainsford KD, Whitehouse MW. Synthesis and anti-inflammatory properties of some aromatic and heterocyclic aromatic curcuminoids. Bioorg Chem 2012;40:30-8.

18. Yanagisawa D, Shirai N, Amatsubo T, Taguchi H, Hirao $\mathrm{K}$, Urushitani $\mathrm{M}$, et al. Relationship between the tautomeric structures of curcumin derivatives and their Abeta-binding activities in the context of therapies for Alzheimer's disease. Biomaterials 2010;14:4179-85.

19. Yvonne CM. Let's not forget tautomers. J Comput Aided Mol Des 2009;23:694-74.

20. Kelotra A, Soumya VG, Kelotra S, Gokhale SM, Bidwai AK. Molecular docking of some herbal-based potential antipsoriasis agents with dihydrofolate reductase. Indian J Drugs Diseases 2012;1:192-9.

21. Manogaran E, Ramanathan M, Mohamed AA. Identification of curcumin targets in neuroinflammatory pathways: molecular docking scores with gsk-3 $\beta$, p38 mapk, cox, ice and tace enzymes. Acta Pol Pharm 2012;69:237:45.

22. Krishnakumar KL, Mathew PU. Metal complexes of heterocyclic unsaturated 1, 3-diketones. Int J Pharm Sci Res 2013;4:1154-8.

23. Krishnakumar KL, Mathew PU. Synthesis, characterization of some heterocyclic curcumin analogues and their copper complexes as antitubercular and antimicrobial agents. Int J Recent Sci Res 2013;4:122-7.

24. Krishnakumar KL, Manju R. Synthesis characterization and comparative study of certain metal-1, 3-diketonates. Int J Pharm Sci Res 2013;4:392-5.

25. Nakamoto K. Infrared spectra of inorganic and coordination compounds. 4th ed. New York: Wiley; 1976.

26. Bellamy LJ. The infrared spectra of complex molecules. $1^{\text {st }}$ ed. London: Academic Press; 1980.

27. Payton F, Sandusky P, Alworth WL. NMR study of the solution structure of curcumin. J Nat Prod 2007;70:143-6.

28. Ben VB, Jelle R, Henk G. Electron ionization mass spectroscopy of curcumin analogues: an olefin metathesis reaction in the fragmentation of radical cations. J Mass Spectrom 1998;33:319-27.

29. Raymond DGJ. The crystal and molecular structure of enol form of 1-phenyl-1,3-betanedione (benzoyl acetone) by neutron diffraction. Acta Crystallogr 1976;B32:2133-8.

30. Haja HA, Ravi G, Dhanasekaran R, Ramasamy P. Studies on organic indole-3-aldehyde single crystals. J Cryst Growth 2000;212:227-32.

31. Sahu VK, Khan AKR, Singh RK, Singh PP. Hydrophobic, Polar and hydrogen bonding based drug-receptor interaction of tetrahydroimidazobenzodiazepinones. Am J Immunol 2008; 4:33-42.

\section{How to cite this article}

- Krishnakumar KL, Mathew Paul Ukken, Manju R. A study on effect of indole as a substituent on a keto-enol tautomer: a synthetic approach on $\beta$-diketone. Int J Pharm Pharm Sci 2017;9(8):219-224 